\title{
De postkoloniale geschiedenis in polyfonie
}

\begin{abstract}
This article focuses on the book Het andere postkoloniale oog, edited by Michiel van Kempen and published in 2020 by the publishing house Verloren. This book had the goal to present never before mentioned aspects of the colonial history of the Netherlands and its influence on cultural practices of the colonised cultures within the last four centuries. Because of the numerous contributions amassed there, the article discusses in depth only a few. These contributions distinguished themselves either through an original academic approach to the topic or the positioning with regard to postcolonial theories usage. The first part of this book involves the need for the re-evaluation of the Dutch colonial history in many parts of the world, to name Suriname as an example. This re-evaluation is highly relevant, as is comes in a time when recent social movements push the mostly unknown parts of the Dutch colonial history into the spotlight. In the second part, this is followed by an attempt to answer the question whether postcolonial theories are essential for the writing bound to the colonial history of the Dutch. As is shown by some contributions, postcolonial theories can stimulate new discussions, especially in cases which do not fit the existing theoretical schemes. And yet, it seems that they are not crucial in discussions about the influence between colonised cultures, though their use might prove fruitful. The article closes with an evaluation of the analysed texts.
\end{abstract}

Keywords: postcolonial studies, Dutch history, history of slavery, cultural exchange, orientalist gaze.

Begrippen zoals 'intersectionaliteit', 'hybriditeit' en 'postkoloniale identiteit' zijn de laatste jaren een belangrijk deel van het historische debat geworden. De BLM- en \#metoo-bewegingen stellen de status quo ter discussie, maar ook in de academische wereld klinkt er een roep om nieuwe perspectieven. Deze stem is des te belangrijker, omdat hij multigenerationeel is. De nieuwe generaties, die de dekolonisatie niet hebben meegemaakt, reiken naar de geschiedenis en vragen met een ongekende kracht naar hun eigen identiteit en plaats in de wereld (Ekotto 2021). De Nederlandse koloniale geschiedenis ontsnapt niet aan deze veranderingen, hoewel er in vergelijking met andere West-Europese landen pas onlangs 
wat meer over deze pijnlijke kwesties wordt gesproken; wat ook geleid heeft tot excuses die Willem-Alexander in 2020 aan Indonesië heeft aangeboden voor de geweldontsporing aan Nederlandse zijde na het uitroepen van de Indonesische onafhankelijkheid. In het licht van deze ontwikkelingen lijkt Het andere postkoloniale oog hoogst actueel te zijn.

Dit boek onder redactie van Michiel van Kempen verscheen in 2020 als verslag van een colloquium georganiseerd op 20 april 2019 door de leerstoel Nederlands-Caraïbische Letteren (Universiteit van Amsterdam) waarvan Van Kempen hoofd is. De 24 bijdragen hebben betrekking op de laatste vier eeuwen van de contacten tussen Nederland en zijn koloniën in de Indische Archipel, Zuid-Afrika en de Caraïbische regio. Zij worden voorafgegaan door een inleiding geschreven door Van Kempen, een feestrede van J.Z. Herrenberg en een essay van Ken Mangroelal over de zich ontwikkelende slavernijherdenking in Nederland. Een groot deel van de auteurs is verbonden aan de leerstoel Nederlands-Caraïbische Letteren en dit komt tot uiting in de thematiek van hun teksten, die zich voornamelijk op de laatstgenoemde regio richten. De hoofdvraag van het colloquium (en ook van de bundel) betreft aspecten die buiten de traditionele postkoloniale studies vallen of die door de onderzoekers niet eerder bekeken konden worden. In zijn inleiding vergelijkt Van Kempen deze aspecten met een vergeten instrumentje in een gereedschapskist: “(...) het ligt er al jaren en jaren, het heeft drie verhuizingen meegemaakt en gaat bij de volgende ook mee, maar waar dient het nou eigenlijk voor?" (Kempen 9).

De onderwerpen die in deze bundel worden behandeld, betreffen niet alleen gepubliceerde literatuur maar tevens andere cultuurproducten, zoals bijdragen waarin auteurs zich op de analyse van manuscripten, muziekinstrumenten, dansen en religieuze praktijken richten. De opbouw van het boek is helder en gebaseerd op een chronologisch criterium. Daarbij wordt begonnen met een analyse van $17^{\mathrm{de}}$-eeuwse liederen over Suriname en Curaçao en afgesloten met opmerkingen over de nieuwe stroming in de Nederlands-Caraïbische literatuur. Vanwege een groot aantal bijdragen wordt hier de focus voornamelijk op teksten gelegd die zich onderscheidden door het besproken thema of de aanpak in het onderzoek. Bovendien worden de hierna besproken bijdragen gebruikt om de volgende vragen te beantwoorden: zijn er zichtbare gelijkenissen te vinden, ondanks de diversiteit van de gepresenteerde onderwerpen in de bundel? In hoeverre worden postkoloniale theorieën gebruikt bij de analyse die onderwerpen, die zich toch voor een groot deel op de postkoloniale geschiedenis baseren?

In de bundel worden meerdere aspecten van de koloniale geschiedenis onder de loep genomen, zowel wat geografische ligging (zij dat nu op Curaçao, in Amsterdam of Semarang) als historische periodes betreft. Daarbij worden levensverhalen van personen uit diverse sociale groepen besproken, zowel van de gewone kleermaker ("Een reis naar Suriname? De gefantaseerde avonturen van 
András Jelky" van Gábor Pusztai, 69-79) als de economische en intellectuele elite (te lezen in "Een 'Surinaams' blijspel in de chicanes van de Amsterdamse elite" van Hilde Neus, 49-67). Dankzij de accumulatie van zulke diverse perspectieven wordt duidelijk welke mogelijkheden er voor de postkoloniale studies nog openstaan en hoe weinig er tot nu toe buiten de grote verhalen is gevorst.

Hoewel er een enorme diversiteit in de gebruikte perspectieven te zien is, is er wel degelijk samenhang tussen de stukken in de bundel. Als voorbeeld zijn er de teksten die het thema van de slavenhandel in de moderne tijd bespreken, zoals "Eerst en pauselijke bul, dan..." van Wouter Krijbolder (255-268). Krijbolder bekritiseert in zijn tekst De levens van Jan Six: een familiegeschiedenis van Geert Mak. ${ }^{1}$ Het boek van Mak, dat in 2016 werd uitgegeven, functioneert volgens Krijbolder als lofzang op de Gouden Eeuw van Nederland en de vergaarde rijkdom zonder de slavenhandel als bron hiervan te noemen. Uit de tekst van Krijbolder blijkt dat er in de Lage Landen nog steeds een fascinatie bestaat voor de Gouden Eeuw, hoewel er daarbij weinig aandacht wordt besteed aan de geschiedenis van de door de Nederlanders tot slaaf gemaakte volkeren. Of met de woorden van Krijbolder: “(...) je zou denken dat de naakte waarheid prevaleert boven misplaatste nostalgie! Maar net zoals bij De levens van Jan Six triomfeert het fictieve boven het feitelijke" (257).

De tekst van Krijbolder klinkt unisono met het essay van Ken Mangroelal, "De vloek van Cham voorbij" (19-29), waarin naar het ontbreken van de slavengeschiedenis in het Nederlandse sociale geweten wordt verwezen, hoewel er teksten in de Nederlandstalige cultuur bestaan die deze functie zouden kunnen vervullen. Ondanks de groeiende humanitaire betrokkenheid bij het lot van slaven en tot slaaf gemaakten in buurlanden zoals Engeland, en evenementen die de slavengeschiedenis herdenken, is er nog weinig sprake van een inclusief wij-gevoel in Nederland dat zou kunnen leiden tot een herziening van de geschiedenis. Het gebrek aan dit gevoel heeft wellicht te maken met de stilte rondom de gruwelijke aspecten van de geschiedenis, zoals de Nederlandse betrokkenheid bij de slavernij, wat Krijbolder en Mangroelal benadrukken.

De stilte waarover Krijbolder en Mangroelal het hebben kan volgens Geert Oostindie haar bron hebben in de verdeeldheid van de verschillende etnische en religieuze groepen die het Nederlandse kolonialisme hebben meegemaakt. Hoewel zij allen een trauma hebben ervaren, verschilt hun koloniale bagage en functioneert het trauma niet als verbindend element. Daarom gaan sommige van de herdenkingspogingen vanuit Nederland, die aan een bepaald aspect van de geschiedenis zijn gewijd, zoals de slavenhandel op Curaçao, in Suriname of

${ }^{1}$ In het boek van Geert Mak wordt de familie Six beschreven, waarin de oudste zoon van het gezin altijd de naam Jan kreeg. Het bekendste lid van de familie is Jan Six (1618-1700), die door Rembrandt werd geportretteerd. De familie Six behoorde tot de kring van de Amsterdamse regenten en breidde dankzij investeringen in onder meer de lakenindustrie haar rijkdom uit. 
Berbice, aan de meerderheid ongemerkt voorbij. De microgeschiedenis van sociale groepen vindt geen weerklank in de macrogeschiedenis van het land: "The government may facilitate and legitimize a broad and inclusive remembering, but it cannot enforce it. Society is simply too heterogeneous and democratic, and the ethnic and historical identification too diverse" (Oostindie 223). Hoe ingewikkeld de situatie ook is, evenementen zoals de Nationale Herdenking Slavernijverleden in 2020 en de excuses van koning Willem-Alexander uit hetzelfde jaar bieden een platform voor discussie, kritiek en verbetering.

Men zou kunnen verwachten dat een bundel gewijd aan de postkoloniale problematiek ook op postkoloniale theorieën gebaseerd is. Bij enkele bijdragen zijn deze theorieën wel zichtbaar. In "Hebi sani e dansi" (91-111) verbindt Aminata Cairo ze met de Caraïbische Feministische Theorie, zoals die van Patricia Mohammed, om zich in de geestelijke praktijken van haar tot slaaf gemaakte voorouders in Suriname te verdiepen. Vanwege een vroegere bezetting door meerdere Europese koloniale mogendheden wordt deze regio gekenmerkt door een enorme diversiteit van volkeren, talen en culturen, wat als gevolg heeft dat er uiteenlopende beelden van mannelijkheid en vrouwelijkheid te ontdekken zijn (Mohammed 8). In haar tekst presenteert Cairo op een gedetailleerde manier de muziek- en danstradities die alle ceremonies in haar culturele kring begeleiden. Hoewel zij deze microgeschiedenis tot in de puntjes beschrijft, blijft zij zich bewust van de kennis van zaken van een gewone lezer; zo zorgt zij voor een overzichtelijke tekst. Door deze combinatie staat haar bijdrage als het ware in het geheugen gegrift.

In tegenstelling tot Cairo kiest Jacqueline Bel in "De inheemse schone" (137-142) voor een discussie met de door haar gekozen theorie, die in dit geval het oriëntalisme van Edward Said is. Daarbij analyseert zij de positie van de Indische huishoudster in vergeten Indische romans. De Indische vrouw wordt in deze romans op een stereotiepe manier gepresenteerd en haar beeld komt overeen met wat Said als de oriëntalistische beschrijving van een Ander presenteert: “(...) irrational, depraved (fallen), childlike, 'different' (...)" (Said 40), maar in enkele gevallen worden in deze romans toch pogingen gedaan om aan het stereotype te ontsnappen en het verhaal van de huishoudster aan het licht te brengen. Deze bijdrage opent de deur naar nieuwe mogelijkheden voor discussie over het creëren van de wereld in de koloniale literatuur in het bijzonder, maar tevens in de algemene literatuur.

De meeste auteurs bespreken de koloniale geschiedenis of de invloeden ervan zonder een postkoloniale theorie te gebruiken. Ter illustratie kan "Een durian als handgranaat" (223-230) van Klaus de Groot dienen. In deze bijdrage wordt naar de 'Indische' gedichten van de Surinaamse dichter Bernardo Ashetu gekeken, waar des dichters duistere en bloederige visie van het nieuwe Indonesië in wordt onthuld. Hij verwijst naar de geschiedenis en cultuur van Nederlands-Indië en Indonesië en hun mogelijke betekenis in het werk van Ashetu, maar gebruikt 
daarbij geen theorie die het bijzondere beeld van Indonesië in de gedichten zou kunnen toelichten. De gedichten ontstonden in de tijd van de Indonesische Onafhankelijkheidsoorlog (1945-1949) en het is zeker dat Ashetu contact met de Indonesische cultuur heeft gehad (of het 'Indische', zoals De Groot dat noemt, 223), hoewel Ashetu zelf het Indische Archipel mogelijk nooit heeft bezocht. Het is duidelijk dat tenminste één van de gedichten naar Max Havelaar verwijst, maar de inspiratie voor de overige teksten is niet onderzocht.

Een ander voorbeeld van een in de koloniale geschiedenis gewortelde tekst is "Gamelan: Surinaams-Javaans erfgoed dat dreigt verloren te gaan" (269-278) van Henriëtte Mingoen, waarin de wereld van de Surinaamse versie van de Indonesische gamelan wordt onderzocht, die langzamerhand in vergetelheid dreigt te raken. In haar tekst volgt Mingoen het spoor van deze muziekinstrumenten, die tegen het einde van de $19^{\text {de }}$ eeuw met Javaanse contractarbeiders naar Suriname zijn gekomen. Zij beweert dat de gamelan belangrijk was voor de identiteit van deze bevolkingsgroep in hun contacten met de plantage-eigenaars, maar zij werkt dit aspect verder niet uit. Mingoen beschrijft tevens welke veranderingen de gamelan qua vorm is ondergaan, hoe hij dankzij de migratiestroom in de jaren 70 van de $20^{\text {ste }}$ eeuw is in Nederland terechtgekomen alsook hoe hij in Suriname een tijd van bloei en verval doorging. De kwestie van het dalende aantal jongeren in gamelangroepen in het algemeen en in de Surinaamse versie ervan in het bijzonder, heeft als gevolg dat enkele van deze groepen zijn opgehouden te bestaan. De kleinere belangstelling onder jongeren wordt ook door andere onderzoekers benadrukt en aangevuld met een zichtbaar afnemende interesse voor het Javaans. Dit gaat gepaard met de belangstelling voor het Nederlands, waarvan de kennis volgens de jeugd noodzakelijk is om progressief te blijven (Allen 212). De bijdrage van Mingoen roept de volgende vragen op: op welke manier kan men de Surinaams-Javaanse cultuur voor de jonge generatie aantrekkelijk maken? Welke veranderingen moet zij ondergaan om opnieuw in de schijnwerpers te staan en tegelijkertijd haar karakter niet te verliezen?

Het andere postkoloniale oog is een aanbevelenswaardige bundel. In de bundel wordt er licht geworpen op de niet voor de hand liggende aspecten van het Nederlandse koloniale verleden en de gevolgen voor de cultuur in de voormalige koloniën. Dit sluit aan bij de recente gebeurtenissen in Nederland en het buitenland, waaronder de excuses van koning Willem-Alexander aan Indonesië voor de geweldontsporing of een groeiende belangstelling voor herdenkingsdagen voor de afschaffing van de slavernij. Daarbij zijn er kwesties die de bijdragen met elkaar verbinden, zoals de slavernijgeschiedenis. Bovendien is het duidelijk dat het gebruik van postkoloniale theorieën niet altijd nodig is in onderzoek naar het koloniale verleden van Nederland en de gevolgen daarvan, hoewel het in enkele gevallen jammer is dat door een gebrek aan een dergelijke theorie een onderwerp niet scherper kon worden belicht. Misschien betekent dat dat auteurs hun werken 
in de toekomst nog kunnen herwerken en verrijken. Daarnaast is het lastig dat er niet voor een uniforme referentiestijl werd gekozen. Daardoor valt het in enkele gevallen moeilijk de bronnen van citaten snel terug te vinden. Niettemin is Het andere postkoloniale oog een waardevolle collectie opstellen.

Michiel van Kempen, Het andere postkoloniale oog, Uitgeverij Verloren, 2020, ISBN 9789087048655,320 pp.

\section{Bibliografie}

Allen, Pamela. "Javanese Cultural Traditions in Suriname". RIMA: Review of Indonesian and Malaysian Affairs, vol. 45, no. 1/2, 2011, pp. 199-223.

Ekotto, Frieda. "Frantz Fanon in the Era of Black Lives Matter". Reframing Postcolonial Studies: Concepts, Methodologies, Scholarly Activisms, geredigeerd door David Kim. Palgrave Macmillan, 2021, pp. 249-259.

Krijbolder, Wouter. “Eerst Een Pauselijke Bul, Dan..." Het Andere Postkoloniale Oog: Onbekende Kanten van de Nederlandse (Post)Koloniale Cultuur En Literatuur. Uitgeverij Verloren, 2020, pp. 255-268.

Mohammed, Patricia. "Towards Indigenous Feminist Theorizing in the Caribbean". Feminist Review, vol. 59, 1998, pp. 6-33.

Oostindie, Gert. Postcolonial Netherlands: Sixty-Five Years of Forgetting, Commemorating, Silencing. Amsterdam University Press, 2011.

Said, Edward. Orientalism. Penguin, 2003.

Van Kempen, Michiel. "Inleiding". Het Andere Postkoloniale Oog: Onbekende Kanten van de Nederlandse (Post)Koloniale Cultuur En Literatuur. Uitgeverij Verloren, 2020, pp. 9-12. 